\title{
On Visions
}

\section{Seán Manning}

\author{
PSYCHOTHERAPIST, DUNEDIN
}

\begin{abstract}
The second in a series on secularism in psychotherapy, this article reprises the idea that paranormal, religious, spiritual or visionary experience is an essential quality of the human mind, and rather than being minimised as merely neurological events or interpreted, for instance as regression, can be given a position of meaning and importance. A distinction is made between the description of neurological or psychological events and their meaning. It is argued that visions can take us forward and give us hope and direction, rather than being considered an aspect of neurosis.
\end{abstract}

\section{Whakarāpopotonga}

Te tuarua o tētahi raupapanga e pā ana ki te wehenga hāhi i rō whakaoranga hinengaro, ka hokia e tēnei tuhinga te ariā, he kōunga waiwai o te hinegaro te wheakoāta whakahirahira,pānga hāhi, wairua rānei, à, kaua e whakaparahakohia he mea raru ā-io, e pēnei i te hokinga whakamuri, me hoatu he tūnga whaihua kairangi hoki. Ka āta tohua te rerekē i waenga i te whakaataranga raru ā-io, raru à-hinengaro rānei me ō rāua tikanga. E whakahauhia ana mā ngā pōhewa tātau e hari whakamua e homai he manawa ora, he ahunga, kaua ko te whakaarohanga he peka nō te mānuka rau.

Keywords: psychotherapy; secularism; religion; spirituality; visions

\section{Prelude}

I believe nothing. Belief is intellectual surrender; "faith" a state of willed self-delusion. (Ehrenreich, 2014, p. 232)

I am saddened by the loss of my religious belief, like leaving forever the comfort of my childhood home, suffused with a warm glow and fond memories. I still have feelings of awe when entering a high-vaulted cathedral or listening to Bach's St. Matthew Passion. Nor can I escape the emotional thrall, the splendour and pageantry, of high Mass. But my loss of faith is an inescapable part of growing up, of maturing and seeing the world as it is. (Koch, 2012, p.116) Manning, S. (2017). On visions. Ata: Journal of Psychotherapy Aotearoa New Zealand, 21(2), 165-176. https://doi.
org/10.9791/ajpanz.2017.15 


\section{ON VISIONS}

\section{Introduction}

In 2015 I wrote a paper arguing that psychotherapy is essentially, and necessarily must remain, a secular discipline (Manning, 2015). I argued there that religion, whether in the sense of large organised structures or belief systems that rely on the existence of spirits or spirit worlds, is not only antithetical to psychotherapy, but is dangerous and often is the source of, or at least a major contributor to extreme violence. These arguments are supported elsewhere, and I am not going to revisit them here, save to thank Paul Solomon for his response to that article (Solomon, 2016). Solomon argued that religion is not inherently dangerous, but arises in response to societal need and to existential anxieties, and is violent to the extent that there is violence threatening the society, as in times of inter-tribal war, becoming more peaceful as societies become peaceful. This is connected, according to Solomon, with a kind of mass splitting and regression to a societal paranoid-schizoid state. I agree with this view. Solomon explained much about why religion and spirituality emerge. I do not see the two views as opposed, save in the responsibility for violence that we attribute to systems of belief that include gods, spirits, angels, and such, which I will not pursue further here.

Having, I believe, established the essentially secular nature of psychotherapy and argued that spiritual, paranormal or religious experience can be understood in terms of biochemistry, this paper revisits spiritual experience - collectively termed 'visions' - not to explain or dismiss them, but to find meaning and direction without the need for spirit worlds, life after death, souls or gods. Biochemical explanations are for this writer accompanied by a feeling of being let down, betrayed by an illusion, as though one sees through a conjuring trick and is thus disinclined to applaud. Profound visionary experience, as far as we can tell, has guided, sustained and terrified us from the beginning of our emergence as a species. It has influenced our decision making, provided familiarity, ritual, comfort, coherence, a way of understanding of our condition and a sense of identity. It has been one of the building blocks of society and a sense of self.

Describing such phenomena in terms of brain function, or analyzing them as regression or paranoid-schizoid functioning or a particular state of mind, while essential for a psychotherapist who wishes to have a layered understanding of the inner world of a patient, misses the central position visions play in constructing a sense of who we are. We can demonstrate that there is a neural substrate for the perception of spirits or gods or travelling outside the body or conversing with the dead or seeing visions, but that must be true of everything we perceive, every action we take. It is not an explanation. The analysis of how a religion arises or why we have extraordinary visionary encounters may have truth and be useful in therapy, but it is overly reductionist, it describes but does not explain.

We might, for instance, imagine that we could discover the neurological events that give us the sense of being moved to the core by a great symphony or by a painting, or we might analyse the experience as a fantasy return to a sublime symbiosis, but we would not claim that these explain the phenomenon. We need more than neuroscience and interpretation. We need meaning, function, purpose.

Spiritual people do really interesting things. Whether it is a "soundscape" created by a big circle of people gathered around a mauri stone, as happened at the 2016 NZAP conference in Napier, or a dawn ceremony to honour our soldiers, or the design of a great mosque or 
cathedral, or a confessional, or the symmetrical perfection of the ceremonial Mass, activities that are prompted by a sense of spirit tend to have a profound effect on us.

This discussion is prompted by a desire to understand these phenomena, without resorting to spiritual explanations, and without minimizing them. Clearly, spiritual experience plays a role in shaping our lives and our societies, so explaining it away in scientific or anthropological terms in a way misses the point. Also, our clients bring their "spiritual selves" into our practices, and it seems a good idea to be able to meet them with acceptance of the importance of a spiritual dimension in the structure of the self, but without recourse to spirit worlds, immortal souls and their like.

In the end, everything is personal. If I rage against the spirituality that threatens to invade the practice of psychotherapy, it is based on anger at losing my own beliefs. I miss the old stone church that affected me so growing up. Even knowing its narrow-minded hypocrisy, the hard-line violent territoriality that lurked beneath its mild Anglican countenance, I miss the communion with God that I experienced as a child. The neuroscientist Christof Koch, in the quote above, described this well.

I miss the righteousness of my adolescent conversion, the beauty of the ceremony, the laying on of hands that marked my confirmation as a member of the Christian community. I miss my later drug-inspired connection with the universe, my Tarot cards, my out-of-body experiences, and my visions, for I have always been drawn to mysticism. The north end of the beach at Karitane where I lived for 20 years always affected me, especially at twilight, knowing that ancient graves were all over that area. I have always felt the presence of the dead and occasionally have seen them, shadows in the shadow, mostly outdoors at dusk, and I have clearly heard their voices. Having discarded my belief in a spirit life, I still value those moments when the world seemed like a picture drawn over a deeper reality that invites and at the same time resists engagement.

Even now, as an atheist, my take on the nature of existence has been described, kindly enough, as "atheist mysticism" (S. Momsen-Bohm, personal communication, April 2016). At the risk of being repetitive, this is what I said in a previous publication that prompted that response.

... while alive we have been something amazing. We have been a part of the moment when the universe woke up. After 13 billion years, which is how long it took to develop complex carbon-based life forms, first manufacturing that elemental building block in the centre of stars, then flinging it into space as the first generation of stars collapsed, allowing planets with carbon to coalesce and ultimately, here on earth, warmed by a second-generation star, conscious self-awareness emerged. Mind was born, matter became aware of itself, developed the capacity for self-reflection and the ability to control its own destiny, to change the course of evolution. One might imagine a future species looking at our history and saying, there, back then with that human mind, that is where it began, that is where the universe learned to think. (Manning, 2015, p. 170)

When I was perhaps 8 years old, I saw a castle from the window on the landing of our Council house in East Belfast. Later, as a young adult, far from home, I decided it must have 


\section{ON VISIONS}

been a reflection of another building on the glass of the partially open window. Returning to that house in my forties, on the death of my father, I remembered the vision, and found, to my surprise, that approaching the landing window still had the power to raise my heart rate, to make me sweat and feel somewhat faint. Examining the scene carefully, I realised that there could have been no reflection. The vision was real. This was a very satisfying thought, for I wanted my vision intact - I did not want it explained away. Having by that time already discarded the idea that visions are a momentary insight into another world, I still wanted it to be real. My hypothesis is that the passing weakness I felt was a return of my childhood helplessness, triggered by a familiar setting, the hallway where I was beaten as a child, that the vision was a hallucination created out of what I had found in books and fairy tales, the product of a creative young mind in need of solace. A primitive Parent lived in the castle, an idealised introject, promising unconditional protection from its unbearable opposite, the primitive negative, the Demon Witch (Steiner, 1974/1995, p. 56).

At the same time, without any sense of conflict or incongruence, I wanted the vision as a supernatural event. I wanted to have seen through a veil, to possibilities beyond the world we mostly inhabit. I wanted it to be special, a gift from another realm to a troubled child. The analysis seems a less satisfying explanation, somewhat mundane, and even while accepting that the mundane interpretation is more truthful, the notion that my vision was a real revelation persists. The desire to have worlds within worlds that reveal themselves through permeable boundaries, to have available the wonderful possibility of many realms, of other planes of existence, still motivates me. Despite no longer being able to believe those things, I am not ready to discount them as mere illusion, primitive projections, neurosis or hallucination.

The reality of mystical experience and its impossibility thus uncomfortably occupy the same conceptual space. I want to explore mystical phenomena not as a kind of by-product, a quirk of our humanity, but as a vitally important function, which, freed from a belief in spirit worlds, parallel dimensions, energy fields, all the trappings of what we refer to as "spirituality", can be valued as central to our wellbeing, individually and collectively.

\section{Dualism's Demise ...}

So what is this need for the mystical? It is tempting to understand it as a universal quality of being human. The literature exploring the need for gods implies so (for example, Armstrong, 1993/1999; Graziano, 2010; Norenzayan, 2013), but at the same time appears to reduce mystical experience to the mundane. The out-of-body experience, for example, becomes a perceptual illusion that can be induced by an experimenter. Ehrsson (2007), for instance, induced an out-of-body experience by touching the participants' body with a rod while simultaneously touching a stranger's body in the same place, in view of cameras.

This kind of evidence is at the same time incontrovertible and unsatisfactory. Experiences which have guided human decision making, as far as we can tell, from the beginning of our history are reduced by science to conjuring tricks, to neurological events. Dualism, René Descartes' conclusion that mind and soul are composed of one substance, and body of another, has had a bad press recently (for instance, Blackmore, 2005). We have learned from studies of subjective experience that the mind, and the sense I have of myself, arises from 
and is continually maintained and challenged by the body. The senses provide information which results in the formation of maps of the body in the brain. Arising initially from the homeostatic self-regulating biochemical machinery that keeps me alive, these are read continuously by higher centres that interpret the state of things, providing the basic evidence for the experience of being. The self, the mind, the soul, are the experience that results.

The neurologist Antonio Damasio's first major book, Descartes' Error (1994) is a good example of this literature. Mind and body are not separate substances; they are indivisible, the one arising from the other. Through a series of books between 1994 and 2011, dealing with consciousness, emotion, and the actual mechanism that generates a sense of self, Damasio takes us on a convincingly secular neurological journey around our experience of being. The soul barely gets a mention; our identity, our sense of self, is entirely generated by our bodies and our brains.

From philosophy, Daniel Dennett (1991) overthrew the myth of the homunculus, the observer/operator within. Also known as the Child (capitalised to avoid confusion with the real child one used to be, in the manner of Berne (1961)) or more specifically, the inner child (Graziano, 2010, p. 58), or the critical inner voice, the real self, or, as early as St Paul (2 Corinthians, 14:16), the inner man (King James Version) or inner self (English Standard Version), this idea crops up regularly, both in psychoanalysis and in pop psychology. All these are variations on the notion that there is an inner controller or observer, or both. This inner person is felt to be somehow more genuine than the outer manifestation, which is a kind of performance, a role or persona, both expressing and hiding the inner being. Dennett called this myth "the Cartesian theatre" in reference to Descartes, and demonstrated how it cannot be true, how the homunculus would need its own inner controller, and so on in an infinite regression.

As Susan Blackmore, a one-time believer and researcher of paranormal phenomena, put it:

The brain is massively parallel and distributed in its design. Information comes in through the senses, and is used to control speech, actions, and other outputs, but there is no central organization; no inner sanctum where the really important bits happen. (Blackmore, 2005, p.18)

Yet every day, in the way we express ourselves, the way we experience ourselves, we demonstrate our belief in our own dual existence.

\section{... and Reprise}

I have an ageing body, it has old man spots, loose skin, wrinkles, and an expanding repertoire of aches and maladies. As a friend of similar age explained, waking up with a new pain, a twinge, an ache, one asks, is this one temporary or will it settle in for the winter?

My deterioration is obvious, often painfully so, and yet inside this troublesome vehicle, at least for the first six or seven hours of each day, I am vitally alive, planning the next adventure, often an activity that will stretch my declining physical ability or be completely beyond it. I am as passionate as ever, though perhaps less impulsive with age. I am in love or 


\section{ON VISIONS}

angry or curious or frightened. I worry about my children and watch with awe as my grandchildren grow and do marvellous, charming, hilarious and dangerous things. Life is, if anything, more interesting than ever. I deny my mortality as efficiently as I ever did. The idea that I am seventy-two is ridiculous. I identify with this body less with each day; I inhabit it, I am in here, but it is not me.

More precisely, I live in a space just behind my eyes, somewhere in the forebrain. I am aware of my torso and my limbs but I do not live there. In dreams, sometimes I inhabit a better, younger body, and I wake with some irritation to find it is not so. I swing my legs off the bed, make my body move. I drive it, I feed it coffee and toast. I act in all these ordinary ways as though I am in my body, wearing it as I wear my clothing, as though Descartes were right and my body and I are different substances. As my body inexorably deteriorates this dualism becomes more obvious, more intense.

I know, with my scientific training, with my informed and reasonably well-read mind, that this is an illusion. Of course I am my body, and beyond a certain point, the deterioration of this body will be accompanied by a deterioration in my mind, until both will die and be gone forever. Dualism is declared by science to be an error, but I intuitively believe it to be true. My body, including my brain, gives rise to the experience of mind, but it is not made of the same "substance". In this Descartes was right. This does not mean that there is some spirit stuff, but mind is definitely not made of matter. Reading Damasio, Dennett and Graziano it seems my mind is another illusion, a kind of trick. But that cannot be all, that is both true and unsatisfactory.

This is a personal illustration of a phenomenon underlying human awareness, that we have two perceptual systems, providing experience and reaching conclusions by different routes, apparently unconnected with each other, and generating quite contradictory schemata on which we base our understanding and action. There is an interpersonal perceptual system, sometimes called intuition or empathy, that rapidly makes decisions about the state of my self and of others, and another, slower, scientific system that evaluates data. If Graziano (2010) is correct, the brain centres that I use to create a sense of self, literally an awareness of myself, are the same as those I use to create an image of you. I attribute qualities of mind to you, as I do to myself, using a combination of observations of your behaviour, resulting in an empathic sensing of your state of mind. Conclusions gleaned from my experience of myself and of interactions with others paint a picture of your mind within mine. It is somewhat simplified, but then I do that with myself as well. The thing is, I sense you as a person within you, just as I experience myself.

Dualism can thus be said to be implicit in the practice of psychotherapy. We imagine that the self resides within the body, within the brain, perhaps within the mind, if we think that self and mind are different. Further, inside the inner self, it has both an aware, or conscious, dimension - that which I think I am - and an unconscious life, of which I am unaware but which determines my behaviour as much as, or more than, the conscious. The self of which we are aware is always somewhat distorted and limited by adaptations or defence mechanisms (depending on your favourite theory), which operate unconsciously, and which become habitual as I develop as an individual. This inner life, as far as I can be aware, is quite consciously hidden from view because hiding how I feel is necessary to the preservation of the community. Psychotherapy attempts an integration, bringing these elements closer 
together, and basic to the scheme is the concept of a mind, of a self (which are not the same, but not different either) that has an independent life within the person, that can direct the person, change their course. I think Descartes would have liked psychotherapy. He might have said that it was a treatment for the soul.

Creating an inner self quite distinct from its vehicle, the body, creating an image of one's self and relationships, happens intuitively, before we are aware of it. It probably happens, according to Graziano (2010), in the temporal-parietal junction in an area of the brain that integrates higher-level perception and specialises in social constructs, particularly to do with intention.

The attribution of intention to others is a fundamental mechanism for a social species such as ours, and we think it is vital in the formation of attachment schema in infancy. It is not so much the parent's behaviour that matters but what the infant perceives as their intention. This process has been teased out in detail by researchers over the past several decades, perhaps beginning with Stern (1985). From the perspective of relational psychoanalysis Benjamin (1995) traced the recognition of the intention of the other and its validity to the third year of life, though the work of Tronick (2007) suggested that it may be an implicit part of much earlier interaction. This capability, recognising that others have different minds from my own, with different intentions, is also a diagnostic indicator, in that its absence or incomplete development is associated with many kinds of distress. Many approaches in psychotherapy, best characterised perhaps by the mentalising school (for example, Allen, Fonagy \& Bateman, 2008), give centrality to this capacity, where the focus of therapy is the search for explanations of how one's mind, and in particular the mind of the other, works.

\section{Spirits, Ghosts and Gods - A Kind of Explanation}

Of course we do not stop there, but attribute intention and state of mind to the weather (the wind is gentle), the land (the mountain is brooding), a child's doll (which is lonely), a car (which has a feminine personality), and so on. It is a short step from here to experiencing gods, ghosts, spirits, energy fields, signs in the natural world that indicate events in a spirit dimension, presences that are unseen but felt, and voices from beyond the grave.

The whole edifice of spirituality, seen from this perspective, is an extension of Descartes' dualism, a model of parallel worlds operating as a conceptual schema within which we interpret our experience. Rather like what we call implicit memory, this way of experiencing ourselves as entities other than our bodies, seeing others as independent or interlinked minds or souls within other bodies, and accepting that there is a spiritual dimension somehow separate from or parallel to the physical world is based on an implicit schema created by the social need to read intentions and interpret relationships within the tribe. These beliefs are perceptual shortcuts, reducing the need to evaluate the intentions of the other by weighing evidence, which just takes too long for everyday life.

\section{In Practice}

Bernard is a committed Christian. He belongs to a proselytising sect, and his greatest pleasure, until recently, was going door-to-door sharing his experience of God. What to this 


\section{ON VISIONS}

writer would be a fearful, thankless task, was transformed for Bernard into the most worthy and pleasurable activity, that of bringing God's word to others. In his early zos Bernard had a conversion experience in which God spoke to him and he felt the Holy Spirit descend on to his head. He showed me where it had entered, at the top of his skull. Since then God has spoken to him a number of times, an experience which he says is accompanied by a wonderful feeling of tranquillity and peaceful optimism. He cannot tell me in words what God says to him, but he experiences it as a direct message, especially for him. Bernard was referred by his GP, who feared that there was some suicidal ideation. Some months previously, Bernard had experienced a sexual attraction towards a woman who worked in a shop near where he lived. He had never spoken to her, other than normal across-the-counter conversation. As far as he was aware, she knew nothing of his thoughts about her. However, his principled honesty demanded that he confess this to his wife, also a Christian convert. She reacted sharply, insisting that he move out, refusing to allow him to see his children and informing the authorities that she feared her husband might do something sexual to them. Bernard has no history of doing anything sexual to any child, nor does he appear to have had any sexual thoughts at all about children, but in his wife's eyes, his ungodly attraction to another woman indicated that he might be capable of any kind of sexual aberration. Bernard believed that it was the work of Satan, who had planted an unwanted sexual desire in him.

He did not meet any criteria for psychosis - neither his speech nor his behaviour were disorganised and his thoughts were coherent. He was not deluded, since his experience of God was in keeping with the culture of an international community of otherwise sane people, and he did not exhibit any negative symptoms. He seemed not too concerned about my lack of faith in God, and did not try to convince me. He said several times over a period of months that he enjoyed our conversations. In many ways he was an agreeable, likeable man. However, he completely rejected my suggestion that such a casual attraction might be a common experience, insisting that Satan was in residence. He could feel the demon within himself.

Thinking psychodynamically, we might observe that Bernard's father was a criminal, a pariah in the community, and that his mother drank heavily, that he was a lonely child, neglected if not actively abused. There was little attunement or even compassion in his early life. We might suggest that God made a much better kind of parent, and that if there was a demon in him, it might be an evil introjected remnant of one or both of his parents. The fragility of his defence might be evident in that it took only a normal human impulse, which he had sensibly resisted, to bring his happiness tumbling down. We would not be surprised to learn that his wife had a history of sexual abuse in childhood.

However, none of this explains the visions, the voice of God, the descent of the Holy Spirit, the existence of the demon, all experiences claimed by human beings throughout recorded history and not confined to the extreme edges of Christianity.

Margaret heard a voice that she attributed to "the universe". It would deliver quite explicit, if mysterious messages, like, "today the way forward is to go back". Like Bernard, her voice was experienced in clear consciousness with no hint of psychosis. She did not believe in Satan, and God was a rather vague, maybe-and-maybe-not sort of idea. Her main symptom was a frequently disastrous emotional dysregulation which involved a lot of yelling, sometimes at me. Using me as a target seemed gradually to reduce her need to direct her 
anger at others, and her tirades were increasingly punctuated with an analysis of penetrating intelligence. In one such moment, when I suggested that the voice might be a product of her own mind, she agreed amicably, but insisted nevertheless that it contained a wisdom that was not hers, and therefore was indeed the voice of the universe. Going back in order to go forward might mean she should explore the past, or that there was some important detail that had been overlooked. Always, the voice was reasonable and gave some kind of direction, though often veiled, and always it turned out to be useful, or was used well by the subject - I am not sure I can tell the difference.

Again, from a psychological point of view, we might suggest that auditory hallucinations are a common accompaniment to abuse histories, and we might guess, correctly, that Margaret had more than her share of childhood trauma. We might even locate the voice in some parental figure, perhaps the enigmatic father, as it is too reasonable to have been constructed out of the crazy mother. Again, though, this kind of explanation misses something important.

It is tempting to suggest that in one of these examples there is more disintegration, more pathology, a religious delusion, and in the other there is a progressive, alter-self showing a way forward. But perhaps this is simply illustrating the therapist's identification with one model and alienation from the other. In both cases, a visionary experience provided a way forward, a way to keep functioning, to express oneself in the world without hurting anyone and without destroying oneself.

Publicity perhaps is the enemy of reason, so it seems audacious to compare these consulting room examples with, for instance, St Teresa's ascent to heaven though meditation (the account she gave may be minimal because, after all, she was writing in response to the inquisition), St Paul's collapse on the road to Damascus, or St Joan's relationship with the Virgin Mary. These are society-changing visions, much more dramatic and dangerous fatally so in Joan's case - but there are enough elements in common with Bernard and Margaret to make the comparison. In all these cases, local or famous, a way forward is indicated.

In the quote at the start of this paper, Barbara Ehrenreich (2014) observes that belief is a kind of intellectual surrender, implying weakness, or lack of rigour. This is an attractively disdainful attitude on the part of science, but it is in itself a failure of nerve. Explaining transformative experience either as neurosis - the term "hallucination" has a sort of derogatory connotation in this context - or as an expression of this or that pathway in the brain certainly balances the notions of spirit worlds and visitations from beyond the grave, but it completely misses the life-changing, profound significance visions have for human life and for human society. Similarly, we can see spiritual belief as a changing imaginary landscape depending on the needs of societies at various stages of their history. Karen Armstrong's History of God (1993/1999) illustrated how the concept of God has changed in response to social conditions, with visionary prophets as the local messengers.

Psychoanalytically, God is the father, powerful and frightening, a projection of the superego, and Mary is the perfect, idealised mother. Politically, religion is an addictive "opiate", a distraction for the common people, persuading them to accept exploitation by, or supported by, the church. Anthropologically, religion assists a society to develop coherence, identity and a code of ethical behaviour, all of which underlie the economic systems that 


\section{ON VISIONS}

allow time for intellectual development to the point where this kind of paper can be written.

These are all valid theses, and all fall short of explaining visionary experience in a way that gives it meaning. In attempting to explain a phenomenon in neurological, social and historical frameworks, they explain it away, diluting what remains one of the most meaningful, life-changing and society-changing experiences of which our species is capable.

Spirituality, in this light, is a shortcut to navigating a world more complex than we can hope to really understand. As Ehrenreich (2014), writing of her own life, observed:

No-one is saying that the universe, as an entity, is alive, and certainly not that it has motives or desires. But the closer we probe, the more it seethes with what looks like life - runaway processes driven by positive feedback loops, emergent patterns, violent attractions, quantum leaps and always, as far ahead as we can see, more surprises. There may be no invisible creaturely 'beings' afoot, either symbionts, parasites or predators. But there are uncountable algorithms at work in the physical world, writhing and reaching, pulling matter and energy into their schemes, acting out of what almost seems to be an unquenchable playfulness. (p. 236)

There is no "nothing", no empty space, but our understanding of what there is remains rudimentary, the complexity of matter being such that we have little chance of reaching a consensus about its nature any time soon. Molecular physics is as full of controversy and argument as any academic field, and such scientific literature as is written for the lay person on the nature of matter and the emergence of living species from it makes demanding reading, so that most people do not bother.

Therefore we require shortcuts, a symbology that is easier to understand. Several times during my training in transactional analysis, I heard an anecdote which I have been unable to source in any literature, so perhaps it is a kind of myth. In this story, it was suggested to Eric Berne that transactional analysis was an overly simplified theory. According to the myth he responded, "Well, I'll stay here at the oversimplified table, and whoever wants can join you at the overcomplicated table over there".

An explanation of creation which resembles things that we understand from our own experience, such as the Heaven and Hell story, works well for us. Trying to get our head around the big bang and the real nature of matter doesn't.

Simplification also serves us when tragedy occurs, where blame, self-blame, recrimination, guilt, tears and fury are all normal reactions. Faced with an overwhelming emotional state, and in particular with horror, we simplify things. We find victims and perpetrators, twodimensional cartoons that are easier than the unfathomable complexity of flesh, perhaps because thinking clearly and feeling strongly make poor companions.

For most people, questions about what we are, how we emerged, and, even less certain, where we are going, require simpler answers than science can offer. Religion, spirituality - I refuse to distinguish between the two, except that the former is more organised and contains more consensus - are a kind of answer. Never mind that they do not stand up to testing, that every investigation into the nature of spirit, the effectiveness of prayer, the existence of ghosts, clairvoyance, telepathy - the entire apparatus of spiritual belief - has supported the null hypothesis; the truth is, such beliefs are handy. They are easy, they require little 
effort and the explanations offered are congruent with our perceptions and satisfying to our hunger for myth, our denial of death, our dreams of immortality, and our love of romance, heroism and storytelling. Above all, because our perceptual mechanisms tell us there are worlds beyond ours, it is relatively easy to achieve consensus when it comes to spiritual belief. We are social animals, and consensus holds us together and gives our societies meaning, form, and an illusion of permanence.

The difficulty of maintaining our intellect as well as engaging with visionary experience has a long academic history. There is a story about Thomas Aquinas, who, when he had finished dictating his Summa Theologiae, laid his head sadly on his arms. When the scribe asked him what the matter was, he said that everything he had written was straw compared with what he had seen (Armstrong, 1993/1999, p. 238). Yet he still tried to offer a logical argument for the existence of God, as had earlier scholars, including $9^{\text {th }}$ and $10^{\text {th }}$ century Muslims in movements called falsafa and kalam, and Jewish Rabbis like Maimonides who used Plato and Aristotle to argue logically for the existence of God. All took the existence of God for granted, and tried to argue why it must be so, from a scientific standpoint.

Sometime in the $12^{\text {th }}$ century in the west, however, the spiritual and scientific traditions flew apart, and have struggled to come together again. It became dangerous to apply scientific process or philosophical discipline to doctrine. The Burgundian bishop Bernard perhaps began it with his persecution of Abelard, a significant figure in the western intellectual revival of the $12^{\text {th }}$ century and who, being physically frail, died a year after facing the Bishop. Bernard's criticism was thus: "He sees nothing as an enigma, nothing as in a mirror, but looks on everything face to face" (Armstrong, 1993/1999, p. 236).

In some ways, this argument must be incomplete, since putting science beside vision without diminishing either, runs up against the power of faith, and our apparent need for it. I am repeatedly admonished for atheism, for how can I not acknowledge the transcendent mystery in our experience? This is, more or less, what Bernard said to Abelard. Alternatively, if I acknowledge the validity of visionary experience, I am told, "You see? You really do believe after all!" One must have one point of view or the other, never both. This position recalls something that was often said to me during the troubles in Northern Ireland. One would be told, "If you are not part of the solution, you must be part of the problem". Visions, the experience of other worlds, other voices, spirits and gods in clear consciousness, without science or analysis demand faith, a denial of reason. Yet they are constructions that are central to our experience and decision making. It is difficult to have visions and reason, but that is the task here.

\section{References}

Allen, J. G., Fonagy, P., \& Bateman, A. W. (2008). Mentalizing in clinical practice. Arlington, VA:

American Psychiatric Publishing.

Armstrong, K. (1999). A history of God: The 4,00o-year quest of Judaism, Christianity, and Islam.

London, UK: Random House. (Original work published 1993)

Benjamin, J. (1995). Like subjects, love objects: Essays on recognition and sexual difference. New Haven, CT: Yale University Press.

Berne, E. (1961). Transactional analysis in psychotherapy. New York, NY: Grove Press. 


\section{ON VISIONS}

Blackmore, S. J. (2005). Consciousness: A very short introduction. Oxford, UK: Oxford University Press.

Damasio, A. (1994). Descartes' error: Emotion, reason, and the human brain. New York, NY: Avon Books.

Dennett, D. C. (1991). Consciousness explained. Boston, MA: Little \& Brown.

Ehrenreich, B. (2014). Living with a wild god: A memoir. New York, NY: Twelve.

Ehrsson, H. H. (2007). The experimental induction of out-of-body experiences. Science, 317 $(5841)$, 1048. https://doi.org/10.1126/science.1142175

Graziano, M. S. A. (2010). God soul mind brain: A neuroscientist's reflections on the spirit world. Teaticket, MA: Leapfrog Press.

Koch, C. (2012). Consciousness: Confessions of a romantic reductionist. Cambridge, MA: Massachusetts Institute of Technology Press.

Manning, S. (2015). On why psychotherapy must be a secular discipline. Ata Journal of Psychotherapy Aotearoa New Zealand, 19(2), 159-172.

Norenzayan, A. (2013). Big gods: How religion transformed cooperation and conflict. Princeton, NJ: Princeton University Press.

Solomon, P. (2016). Response to Seán Manning's article: "Why psychotherapy must be secular". Ata Journal of Psychotherapy Aotearoa New Zealand, 20(1), 89-95.

Steiner, C. (1995). Scripts people live. New York, NY: Bantam Books. (Original work published 1974)

Stern, D. $(1985)$. The interpersonal world of the infant: A view from psychoanalysis and developmental psychology. New York, NY: Basic Books.

Tronick, E. (2007). The neurobehavioral and social-emotional development of infants and children. New York, NY: W. W. Norton.

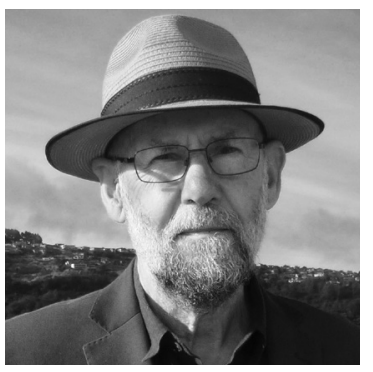

Seán Manning (MSc, DipSW, DipGrad, MNZAP, TSTA, Registered Psychotherapist) is a psychotherapist in Dunedin. His academic and professional background is in psychology and social work. He specialises in the treatment of men with addictions, criminality and violent behaviour, in prison, therapeutic community and community-based programmes. Raised in Belfast, Northern Ireland, he has lived in Aotearoa New Zealand since 1975. Seán is 72 years old and has three grown up children and two grandchildren. He has held a number of offices in professional associations, is a former president of the NZAP, and recently has been working on having a social life. His limited abilities with Maori and Spanish are still a lot better than his command of Irish. His addiction to collecting musical instruments is almost under control though his ability to play them lags behind. Sometimes unreasonable and grumpy, Seán is passionate about psychotherapy and is intensely interested in how it works and what happens in the human brain as a result. He has authored a report summarising the effectiveness of psychotherapy and a number of papers on antisocial behaviour, the unconscious and the essentially secular nature of psychotherapy. 